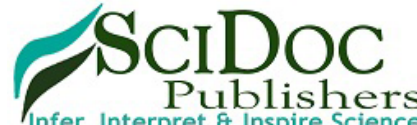

\author{
International Journal of Dentistry and Oral Science (IJDOS) \\ ISSN: 2377-8075
}

\title{
Evaluation of the Effectiveness of Sodium Hypochlorite Gel Application in Removing Dental Plaque Before Pit and Fissure Sealant Placement: A Randomized Controlled Clinical Trial
}

Lilian Azrak ${ }^{1}$, Nada Bshara ${ }^{2}$, Muaaz Alkhouli ${ }^{*}$

${ }^{1} \mathrm{PhD}, \mathrm{MSc}$, DDS, Department of Pediatric Dentistry, Faculty of Dentistry, Damascus University, Syria.

${ }^{2}$ Professor at Department of Pediatric Dentistry, Faculty of Dentistry, Damascus University, Syria.

${ }^{3}$ MSc, DDS, Department of Pediatric Dentistry, Faculty of Dentistry, Damascus University, Syria.

\section{Abstract}

Objectives: To evaluate the cleaning efficacy of $2.2 \%$ sodium hypochlorite gel compared to pumice powder on the permanent first molars before applying the sealant.

Materials and Methods: Sixty sound molars were recruited from 30 patients (7-10 years) in which their plaque on the occlusal surfaces of permanent first molars was stained (Mira-2-Tone) and photographed. Molars were selected randomly and divided into 3 groups: G1 pumice powder ( $\mathrm{n}=30$ molars) G2: sodium hypochlorite gel applied for 30 seconds ( $\mathrm{n}=30$ molars), G3: sodium hypochlorite gel reapplied for another 30 seconds ( $\mathrm{n}=30$ molars). Then the Mira- 2tone was applied and photographed before and after the cleaning. In a conventional picture editing program. The occlusal surface and plaque were measured in pixels and the relative proportion of occlusal plaque was calculated. Samples from eachgroup were etched with $37 \%$ phosphoric acid gel for 15 seconds followed by placement of a sealant.

Results: There was astatistically significant difference between after and before cleaning in the three analyzed groups ( $T$ test: $\mathrm{p}<0.05)$. The percentage of variation in coloring rate was $68 \%$ for the G3 group, while the percentage of variation in coloring rate G2 and G1 group was $44 \%, 39 \%$ respectively.

Conclusion: The use of $2.2 \% \mathrm{NaOCl}$ gel for 60 seconds had a better cleaning efficacy comparing pumice powder and was able to remove dental plaque before applying the sealant.

Keywords: Sodium Hypochlorite Gel; Pits and Fissures; Variation in Coloring Rate.

\section{Introduction}

As dental caries becomes a public health problem over the last few decades, a big advance has been made in caries prevention. suppression of dental plaque formation, mechanical removal of dental plaque, fluoride treatment either topically or systemically, pit and fissure sealants application and dental health educationalprograms have had an undeniable effect on caries prevention recently [1].

Pit and fissure sealants are considere done of the effective modes in the prevention of dental decay in caries-susceptible teeth by creating a physically protective barrier that keeps the cariogenic bacteria away from the nutrients needed and prevents the enamel surface from being demineralized. These preventive characteristicsare mainly obtained and maintained as long as the sealantsremain completely intact and bonded in place $[1,2]$.

On the other hand, sealant placement is a very sensitive technique because there is a risk of leaving some residual material, moisture, or air bubbles inside of the fissures preventing proper sealant penetration and endangering optimal retention and structural integrity [2, 3]. Moreover, inadequate removal of dental plaque before etching can harm sealant retention or lead to microleakageincreasing the probability of caries development [4].

Both invasive and non-invasive methods are used in the purpose

\footnotetext{
*Corresponding Author

Muaaz Alkhouli MSc, DDS,

Department of Pediatric Dentistry, Faculty of Dentistry, Damascus University, Syria. Tel: 00963966133383

E-mail: muaaz.alkhouli@outlook.com
}

Received: May 07, 2020

Accepted: July 08, 2020

Published: July 15, 2020

Citation: Lilian Azrak, Nada Bshara, Muaaz Alkhouli. Evaluation of the Effectiveness of Sodium Hypochlorite Gel Application in Removing Dental Plaque Before Pit and Fissure Sealant Placement: A Randomized Controlled Clinical Trial. Int J Dentistry Oral Sci. 2020;7(7):776-780. doi: http://dx.doi.org/10.19070/2377-8075-20000152 
of cleaning and preparing the enamel fissures prior to etching and sealant application. However, those methods have delivered contrasting and even contradictory results $[5,6]$. Dry brushing, pumice prophylaxis with rubber cups, fissure burs, adhesive agents, lasers, abrasion with air, sodium bicarbonate, or aluminum oxide particles and prolonging the etching time are some examples of techniques currently suggested in pediatric dentistry to reduce the plaque content within pits and fissures [7,8].

Despite the hypothesis that mentioned that pumice powder has some residues in the pits and fissures after 60 seconds from washing or 30 seconds from etching [9], Pumice prophylaxis is still used as a routine basis before sealant application [10, 11]. In return, sodium hypochloritegel has not been studied as a plaque removal agent within pits and fissures before sealant application to the best of our knowledge although it has been used widely in dental procedures due to its antibacterial and deproteinizingeffect.

Therefore, this trial was aimed to evaluate the use of different methods to clean occlusal pits and fissures: pumice prophylaxis, 30 seconds application of $\mathrm{NaOCl}$ gel $2.2 \%$ and 60 seconds application of $\mathrm{NaOCl}$ gel $2.2 \%$.

\section{Materials and Methods}

\section{Study design}

This study was a randomized controlled clinical double-blinded trial composed of two teeth of each participant (split mouth study). Thirty cooperative children (15 male and 15 female) aged between 7-10 years participated in this trial. They were all recruited from pediatric dentistry department of Damascus University. In total, 60 molars were enrolled in the study and they werelower first permanent molars which were caries free based on visual examination according to ICDAS II detection system (code 0 ). The trial was conducted in accordance with the declaration of Helsinki and approved by the Research Ethics Committee of Faculty of Dentistry of Damascus University.

\section{Study groups}

The teeth were assigned into three groups; Group 1: teeth were cleaned with pumice powder (control group) ( $\mathrm{n}=30$ molars), Group 2: teeth were cleaned with sodium hypochlorite gel applied for 30 seconds ( $n=30$ molars), Group 3: teeth of Group 2 were washed thoroughly and reapplied sodium hypochlorite gel for another 30 seconds ( $\mathrm{n}=30$ molars). Randomization was done using the website www.randomizer.org in order to aid in allocating teeth into groups randomly.

\section{Intervention}

A signed informed consent was obtained from the parents of all enrolled children. The plaque was detected using plaque disclosing agent (Mira-2-tone, Hager \& Werken, Germany) before cleaning of the pits and fissures and after cleaning them in order to evaluate the effectiveness of the cleaning method used. The following steps were followed for each tooth: 1-rubber dam isolation. 2 Cleaning pit and fissure surfaces either by using pumice powder, $\mathrm{NaOCl}$ gel for 30 seconds or $\mathrm{NaOCl}$ gel for 60 seconds 3-Rinsing and drying 4 - Etching pits and fissures for 30 seconds (Etchant $37 \%$, 3M, USA) 4 - Rinsing and drying again 5- Application of sealant material (Helioseal,IvoclarVivadent, Liechtenstein). 6- polymerization using light cure device for 20 seconds. 7 - Occlusion assessment using articulation paper.

Teeth were photographed from over the occlusal surface in order to digitaize the images through transferring them to the program Adobe Photoshop (V6.0, Adobe Systems Ltd, Europe) and measuring a definite outlined surface in these reformatted images in pixels. First, an outline of the occlusal surface was done by connecting lingual and buccal cusp tips through the descending cutting edges of the cusps and marginal ridges of the occlusal surfaces (Figure 1). Then, the outline of the disclosed area of the pits and fissures surface was taken and the ratio between both the occlusal surface and the disclosed surface was calculated to get the relative proportion of occlusal plaque, this was named the color coefficient average of the occlusal plaque, which is calculated using the following equation:

Color coefficient average of the occlusal plaque $=($ coloration of pits and fissure (pixel))/(occlusal surface (pixel) $) \times 100$

Two blinded examiners carried out the outlining and this method was done twice for each tooth (before and after cleaning).

\section{Statistical Analysis}

The collected data were introduced into SPSS software version 23 (IBM Corp., Armonk, USA). Kolmogorov-Smirnov test was used to check if the data are normally distributed, and it concludes that they were normally distributed. The level of significance (P-value) was set at 0.05 and the power of study was $90 \%$. T-student test was used to conclude if there is a difference in the level of cleaning that is statistically significant within each group. Bonferroni

Figure 1. Outlining the Occlusal Surface.

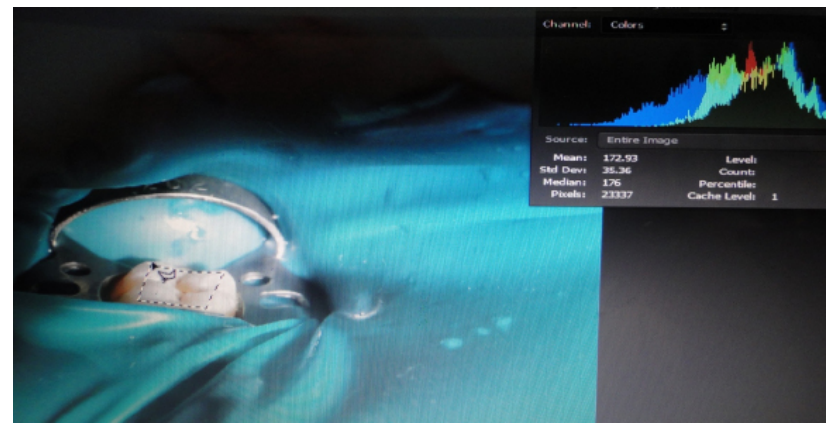


Test was also used to show if the dual difference between the groups was significant.

\section{Results}

Data were collected from 30 children (15 male and 15 female), from whom 60 teeth were randomly assigned into the three groups. The mean age of children in control group, $\mathrm{NaOCl}$ (30 sec) group and $\mathrm{NaOCl}(60 \mathrm{sec})$ group was 9.1, 8.6 and 7.9 years, respectively. Figure 2 shows the CONSORT flow chart concerning the participants of this trial.

The plaque disclosing agent was used twice for each tooth, before and after cleaning. After each application, the color coefficient average of the occlusal plaque was calculated. Then, the variance between the two values (before and after) was calculated. The variance values were as follows: The use of $\mathrm{NaOCl}$ for 60 seconds had the highest variation in coloring rate $(-19.59)$, then the use of $\mathrm{NaOCl}$ for 30 seconds, then pumice powder $(-13.78,-9.22)$, respectively.

The study data were distributed normally. For that reason, t-student test was done in order to study the dual differences between the color coefficient averages before and after cleaning of each method (Table 1). T-student test showed that all methods of cleaning were effective in plaque removal as there was a significant difference $(\mathrm{P}=0.000)$ when comparing the two stages of intervention (before and after cleaning). In addition, in figure 3 , the change in Color coefficient average of the occlusal plaque (Pixels) is demonstrated within each group.

Bonferroni test was used to report dual differences between the percentages of variation in coloring rate according to the method of cleaning. There werestatistically differences between the use of $\mathrm{NaOCl}$ for 60 seconds and pumice powder $(\mathrm{P}$-value $<0.05)$ in the percentages of variation in coloring rate (Table 2).

Figure 2. CONSORT flow chart of the trial.

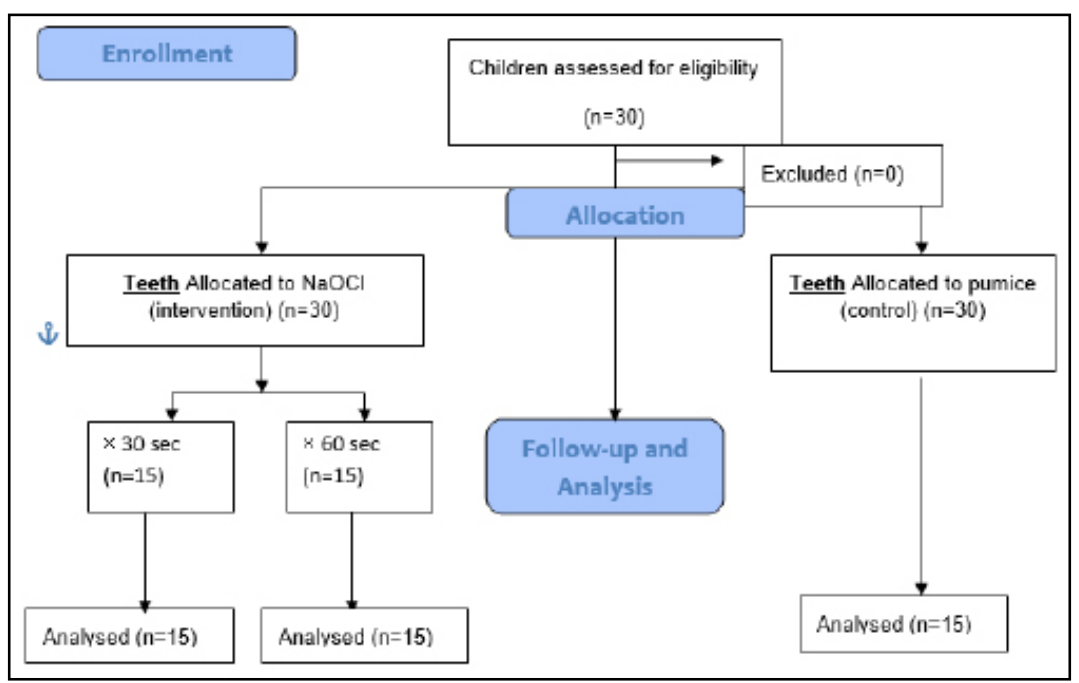

Table 1. t-student analysis to study the significance of cleaning efficacy in each group.

\begin{tabular}{|c|c|c|c|c|c|c|c|}
\hline $\begin{array}{l}\text { Method of } \\
\text { Cleaning }\end{array}$ & Cleaning Stage & $\mathbf{N}^{*}$ & $\begin{array}{l}\text { Coloring coef- } \\
\text { ficient average }\end{array}$ & $\begin{array}{l}\text { Standard } \\
\text { deviation }\end{array}$ & variation & $\begin{array}{l}\text { Calculated } \\
\text { t value }\end{array}$ & P-value \\
\hline \multirow{2}{*}{$\begin{array}{l}\mathrm{NaOCl} \mathrm{X} 1(30 \\
\text { Seconds) }\end{array}$} & Before Cleaning & 30 & 28.66 & 21.55 & \multirow{2}{*}{13.78} & \multirow{2}{*}{-4.945} & \multirow{2}{*}{$0.000^{*}$} \\
\hline & After Cleaning & 30 & 14.88 & 8.95 & & & \\
\hline \multirow{2}{*}{$\begin{array}{l}\mathrm{NaOCl} X 2(60 \\
\text { Seconds) }\end{array}$} & Before Cleaning & 30 & 28.66 & 21.55 & \multirow{2}{*}{19.59} & \multirow{2}{*}{-19.59} & \multirow{2}{*}{$0.000^{*}$} \\
\hline & After Cleaning & 30 & 9.07 & 7.43 & & & \\
\hline \multirow{2}{*}{ Pumice Powder } & Before Cleaning & 30 & 22.36 & 9.45 & \multirow{2}{*}{9.22} & \multirow{2}{*}{-7.627} & \multirow{2}{*}{$0.000 *$} \\
\hline & After Cleaning & 30 & 13.14 & 5.98 & & & \\
\hline
\end{tabular}

$* \mathrm{~N}=$ number of teeth

* Statistically significant

Table 2. Bonferroni test for the dual differences between the percentages of variation in coloring rate.

\begin{tabular}{|c|c|c|c|c|}
\hline Method of Cleaning & Method of Cleaning & Difference between two averages & Standard error & P-value \\
\hline \multirow{2}{*}{$\mathrm{NaOCl}$ X1 (30 Seconds) } & $\mathrm{NaOCl} \mathrm{X2} \mathrm{(60} \mathrm{Seconds)}$ & 24.38 & 4.31 & $0.000^{*}$ \\
\cline { 2 - 5 } & Pumice Powder & -4.59 & 4.31 & 0.869 \\
\hline $\mathrm{NaOCl}$ X2 (60 Seconds) & Pumice Powder & -28.97 & 4.31 & $0.000^{*}$ \\
\hline
\end{tabular}

*statistically significant 
Figure 3. Change in Color coefficient average of the occlusal plaque (Pixel).

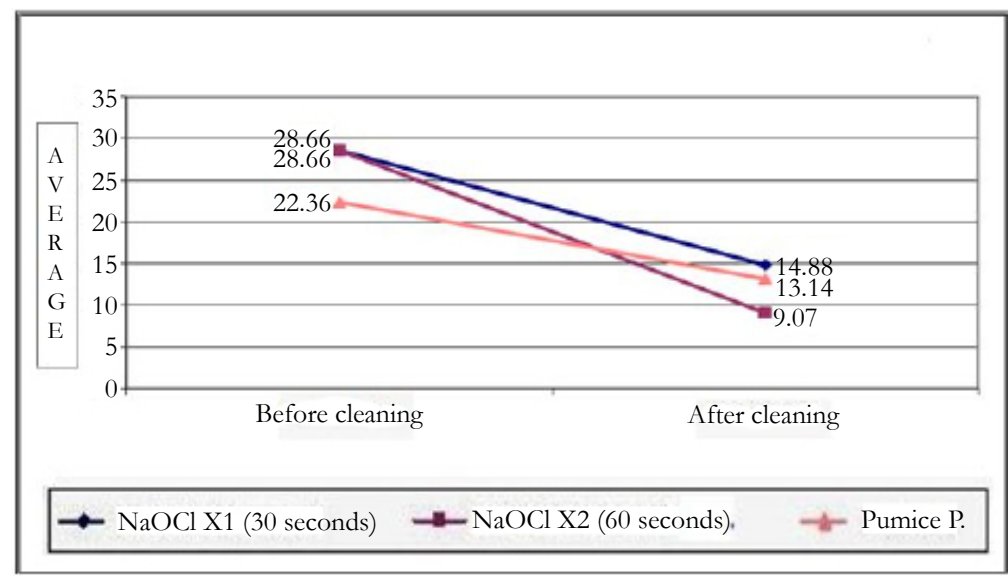

The success of the cleaning method was measured by the percentage of variation in coloring rate in the occlusal surface, considering this the applying of $\mathrm{NaOCl}$ for 60 second was the best cleaning method with percentage of $67.92 \%$.

\section{Discussion}

Resin-based pit and fissure sealant is a caries preventive agent that is applied to caries-susceptible teeth by bonding to the enamel surface micromechanically, averting access by cariogenic bacteria to the place of nutrients [5]. Acid etching does not eliminate the organic content on the enamel surface, which is primarily composed of protein [12]. The collagen fibril network remained undamaged after dentin demineralization with phosphoric acid. The organic content comprises only $1 \%$ of the enamel and it cannot be entirely removed with forgetting the enamel crystals' proteins [3]. This arise the need of an appropriate preparing method that can achieves a total removal of the dental plaque and helps etching to be effective [13].

The present study consisted of 60 erupted permanent molars in children between 7 years and 10 years of age. Pumice powder, $\mathrm{NaOCl}$ gel for 30 seconds and $\mathrm{NaOCl}$ gel for 60 seconds were the groups to which teeth were randomly allocated for cleaning of the pit and fissure surface with the use of phosphoric acid for etching. The study was designed as a split mouth study to standardize patient associated factors such as the cooperation during the procedure and the oral hygiene.

Plaque disclosing agent was applied two times for each tooth, before and after cleaning. In order to assess the effectiveness of each agent in plaque removal, the occlusal surface was photographed and digitalized to calculate the surface of plaque in pixels. Furthermore, the color coefficient average was taken by calculating the ratio between the occlusal surface and the coloration of the pit and fissure surface. This aids in overcoming the possible problems associated with distance difference between the lens of the camera and the occlusal surface. This method is a valid and reliable one according to many studies $[14,15]$.

In this trial, the method of pretreating the enamel surface by deproteinising with sodium hypochlorite gel $(\mathrm{NaOCl})$ for $60 \mathrm{sec}-$ onds prior to etching has proven to be an effective method $(68 \%)$. This can be justified for improving the quality of conditioning by significantly removing organic elements and denaturing proteins present in both the enamel and the acquired pellicle.

The findings of this study is in agreement with Espinoza et al., in vitro study, which demonstrated that the deproteinisation process of $\mathrm{NaOCl}$ increases the conditioned area and improves the quality of enamel acid etching, optimizing the retentive surface and sealant bond strength. However, their study used the solution form of the $\mathrm{NaOCl}[16]$.

Sodium hypochlorite is introduced commercially in two different forms, the solution and the gel. The later form (gel) was used to dentistry to overcome some of the solution related disadvantages. The gel form was used in this study as it is more controllable in application than the solution.

$\mathrm{NaOCl}$ solution has been used in endodontics for its antimicrobialpropertiesand ability to dissolve the organic material from the root canal space without damaging intact dentinal tissues [17]. Moreover,incleaning the enamel surface, sodium hypochloritereachesthe organic components and distinct chemical reactionsdevelop including saponification and neutralization. These reactions lead to liquefaction of the organicmaterial in enamel without injuring the enamel structure, a process referred to as deproteinisation [18]. Because the gel has the same active components and properties with the solution, this may explain the better results of using $\mathrm{NaOCl}$ gel in this study comparing with pumice powder thatdoes not have the similar mechanism of action.

According to the in vitro study conducted by Garrocho, the deproteinisation caused by $\mathrm{NaOCl}$ prior to acid etching improved the bonding to enamel. This was caused by increasing the surface area of etched enamel after pretreatingthe occlusal enamel with 60 seconds of $\mathrm{NaOCl}$ solution. Therefore, he suggested the enamel treatment method prior toacid etching to increase the useful clinical life of resin sealants placed on primary orpermanent molars. [19].

This study revealed that the use of $\mathrm{NaOCl}$ for 30 seconds was effective in relatively equal percentage to the use of pumice powder $(44 \%)$ and $(39 \%)$, respectively. While the application of $\mathrm{NaOCl}$ gel for 60 seconds was more effective with $68 \%$ success rate. This can be due to the time of $\mathrm{NaOCl}$ applying according to Gomes et al, who indicates the increasing results of the cleaning capacity of $\mathrm{NaOCl}$ with the increasing time of applying [20]. 


\section{Conclusions}

Within the limitations of this study, we can conclude that applying $\mathrm{NaOCl}$ gel for 60 seconds is effective in cleaning the pit and fissure surface to remove the dental plaque prior to sealant placement, with success rate of $68 \%$.

\section{References}

[1]. Simonsen RJ. Pit and fissure sealant: review of the literature. Pediatr Dent. Sep-Oct 2002;24(5):393-414.Pubmed PMID:12412954.

[2]. Simonsen RJ. Retention and effectiveness of dental sealant after 15 years. J Am Dent Assoc. 1991 Oct;122(10):34-42.Pubmed PMID:1835987.

[3]. Ramakrishna Y, Bhoomika A, Harleen N, Munshi AK. Enamel deproteinization after acid etching-is it worth the effort. Dentistry. 2014 Jan 1;4(2):2-6.

[4]. Cooley RL, McCourt JW. Evaluation of by SEM, microleakage, and fluoride release. Pediatric dentistry. 1990 Feb;12(1):39.

[5]. Hegde RJ, Coutinho RC. Comparison of different methods of cleaning and preparing occlusal fissure surface before placement of pit and fissure sealants: An in vivo study. Journal of Indian Society of Pedodontics and Preventive Dentistry. 2016 Apr 1;34(2):111.

[6]. Camacho Castro, L. and A. Claudia Galvão, Comparison of three different preparation methods in the improvement of sealant retention. J Clin Pediatr Dent. 2004 Spring;28(3):249-52.Pubmed PMID:15163154.

[7]. Agrawal A, A Shigli, Comparison of six different methods of cleaning and preparing occlusal fissure surface before placement of pit and fissure sealant: an in vitro study. J Indian Soc Pedod Prev Dent. Jan-Mar 2012;30(1):51-5. Pubmed PMID:22565518.

[8]. Muller-Bolla M, Lupi-Pégurier L, Tardieu C, Velly AM, Antomarchi C. Retention of resin-based pit and fissure sealants: a systematic review. Community dentistry and oral epidemiology. 2006 Oct;34(5):321-36.

[9]. Asquinazi ML, Jasmin JR, Muller M, Magne J. In vitro study of 99m-Technetium labeled pumice: Penetration in fissures. Journal of Dentistry for Chil- dren. 1999 Nov 1;66(6):387-9.

[10]. Blackwood JA, Dilley DC, Roberts MW, Swift EJ. Evaluation of pumice, fissure enameloplasty and air abrasion on sealant microleakage. Pediatr Dent. 2002;24(3):199-203.Pubmed PMID:12064490.

[11]. Ansari G, Oloomi K, Eslami B. Microleakage assessment of pit and fissure sealant with and without the use of pumice prophylaxis. Int J Paediatr Dent. 2004 Jul;14(4):272-8.Pubmed PMID:15242384.

[12]. Van Landuyt K, De Munck J, Coutinho E, Peumans M, Lambrechts P, Van Meerbeek B. Bonding to dentin: smear layer and the process of hybridization. InDental Hard Tissues and Bonding. Springer, Berlin, Heidelberg. p. 89-122.

[13]. Gwinnett, A. Histologic changes in human enamel following treatment with acidic adhesive conditioning agents. Arch Oral Biol. 1971 Jul;16(7):731-8. Pubmed PMID:5283531.

[14]. SSmith RN, Brook AH, Elcock C. The quantification of dental plaque using an image analysis system: reliability and validation.JClinPeriodontol. 2001 Dec;28(12):1158-62.Pubmed PMID:11737514.

[15]. Splieth CH, Nourallah AW. An occlusal plaque index. Measurements of repeatability, reproducibility, and sensitivity. Am J Dent. 2006 Jun;19(3):1357.Pubmed PMID:16838474.

[16]. Espinosa R, Valencia R, Uribe M, Ceja I, Saadia M. Enamel deproteinization and its effect on acid etching: an in vitro study. J Clin Pediatr Dent. 2008 Fall;33(1):13-9. Pubmed PMID:19093646.

[17]. Mohammadi Z. Sodium hypochlorite in endodontics: an update review. Int Dent J. 2008 Dec;58(6):329-41.Pubmed PMID:19145794.

[18]. Ahuja, B, Yeluri R, Baliga S, Munshi AK., Enamel deproteinization before acid etching-A scanning electron microscopic observation. J Clin Pediatr Dent. Winter 2010;35(2):169-72.Pubmed PMID:21417119.

[19]. Garrocho-Rangel A, Lozano-Vázquez C, Butrón-Tellez-Girón C, EscobarGarcía D, Ruíz-Rodriguez S, Pozos-Guillén A. In vitro assessment of retention and microleakage in pit and fissure sealants following enamel pre-etching with sodium hypochlorite deproteinisation. Eur J Paediatr Den. 2015 Sep;16(3):212-6.Pubmed PMID:26418924.

[20]. Gomes BP, Ferraz CC, ME V, Berber VB, Teixeira FB, Souza-Filho FJ. In vitro antimicrobial activity of several concentrations of sodium hypochlorite and chlorhexidine gluconate in the elimination of Enterococcus faecalis. Int Endod . 2001 Sep;34(6):424-8.Pubmed PMID: 11556507. 